\title{
O DECLINIO NA DESIGUALDADE DA ESCOLARIDADE NO BRASIL E SEUS EFEITOS NA DESIGUALDADE DE RENDIMENTOS*
}

\author{
David Lam** \\ e \\ Deborah Levison***
}

Resumo

Dados de Amostragem Domiciliar demostram que os homens brasileiros nascidos entre 1925 e 1963 conheceram um crescimento continuado na escolaridade média e um declinio significativo na desigualdade em escolaridade. A variāncia nos anos de escolaridade cresceu para as coortes nascidas até 1950, e declinou continuamente para os grupos mais recentes. A decomposição da equação de rendimentos, segundo a teoria do capital humano, indica que aumentos na escolaridade tendem a reduzir a desigualdade nos rendimentos para o período de 1967 a 1985, devido a reduçōes em ambas as variâncias da escolaridade e dos retornos da educação. Entretanto, estas melhorias são mais do que compensadas pelo crescimento de outras fontes de desigualdade. Embora o crescimento líquido da desigualdade dos rendimentos entre 1976 e 1985 seja in quietante, a redução na desigualdade da escolaridade representa uma melhora fundamental nos determinantes da desigualdade dos rendimentos no Brasil que terá efeitos benéficos por décadas.

\section{Abstract}

Household survey data demonstrate that Brazilian males born between 1925 and 1963 experienced steady increases in mean schooling and significant declines in schooling inequality. The variance in years of schooling increased for cohorts born up until 1950, with steady declines for more recent cohorts. Decomposition of a standrad human capital'earnings equation indicates that trends in schooling tended to reduce earnings inequality from 1976 to 1985 ,

*Uma versão preliminar desie artigo foi apresentada no Encontro da ANPEC, Fortaleza, Brasil, em Dezembro de 1989. Os autores agradecem as sugestōes de Ricardo Paes de Barros, Guilherme Sedlacek, José Guilherme Almeida Reis e de dois pareceristas anónimos. Os autores desejam tambem agradecer a excelente assistência de pesquisa de Robert Schoeni. Este artigo contou com os auxílios da Fulbright Commission, do Program for International Partnerships da Universidade de Michigan e do Instituto de Planejamento Econômico e Social - IPEA/RIO.

**Professor Associado, Departamento de Economia e Centro de Estudos Populacionais da Universidade de Michigan.

***Bolsista de Pós-doutorado no Centro de Crescimento Econômico da Universidade de Yale.

R. de Econometria Rio de Janeiro v. X, no 2, p.243-278 novembro 1990 
due to reductions in both the variance of shooling and in return to shooling. These improvements were more than offset, however, by increases in other sources of inequality. Although the net increase in earnings inequality from 1976 to 1985 is disturbing, the reduction in schooling inequality represents a fundamental improvement in the determinants of eranings inequality in Brazil that will have beneficial effects for decades.

\section{Introduçāo.}

A relação existente, em dada população, entre a distribuição dos anos de escolaridade e a distribuição de renda tem sido, desde muito, um dos temas centrais da literatura sobre desigualdade de renda. Numerosos estudos estimaram em que medida a distribuição da escolaridade explica,em uma dada população e também entre várias, as desigualdades de rendimentos. Incluem-se aí trabalhos diretamente relacionados aos modelos de capital humano, tais como Becker e Chiswick (1966), Mincer (1974), bem como pesquisas com interpretações teóricas alternativas, como Jencks (1972) e Tinbergen (1972).

Pesquisas relativas aos países em desenvolvimento têm dirigido particular atenção a questão de como o nível de escolaridade afeta a desigualdade de rendimentos. Vários autores têm mostrado [e.g. Chiswick (1971), Knight e Sabot (1978) e Marin e Psacharopoulos (1976)] que o efeito do crescimento da escolaridade sobre a desigualdade de rendimentos é de difícil previsão a priori, dependendo das mudanças específicas ocorridas nos diferentes niveis de escolaridade, da relação entre escolaridade e rendimentos e da mudança desta relação à medida em que o próprio processo de escolaridade avança. Alguns trabalhos, como Winegard (1979), Ram (1984) e Tilak (1989), procuraram esclarecer empiricamente da relação entre a desigualdade de renda, medidas de escolaridade média e cesigualdade de escolaridade via análise de cross-section envolvendo vários países. Tais análises, contudo, fornecem resultados empíricos conflitantes e, por uma série de razões, apresentam apenas uma descrição limitada da relação entre mudanças na distribuição da escolaridade e mudanças na distribuição de rendimentos ao longo do tempo.

O objetivo do presente trabalho é analisar as mudanças na distribuição da escolaridade ocorridas nas úitimas décadas em um país em vias de desenvolvimento, o Brasil, e os efeitos dessas modificações na sua distribuição de renda. O Brasil, com seu alto grau de desigualdade de renda e baixos niveis de escolaridade, 
se comparado a outros países com renda per capita semelhante, apresenta-se como particularmente apropriado para a análise proposta. No extenso debate sobre desigualdade de renda no Brasil, o papel da educação tem sido enfatizado freqüentemente, como acontece nos trabalhos bastante conhecidos de Fishlow (1972) e Langoni (1973, 1977). O sistema educacional brasileiro é freqüentemente criticado por produzir, simultaneamente, baixos níveis e desigual distribuição da escolaridade, se comparado a países com níveis de renda semelhantes. Contudo, tem havido pouca análise sistemática das mudanças na distribuição da escolarização ao longo do tempo, tanto no Brasil como em outros países em vias de desenvolvimento.

O presente artigo analisa as mudanças na distribuição da escolaridade no Brasil, para os homens nascidos entre 1925 e 1963. Mostramos que o aumento na média dos anos de escolaridade durante o mencionado período foi acompanhado por uma persistente redução da desigualdade na escolaridade, medida pelo coeficiente de variação e por outras medidas invariantes em relação à média. A variância referente aos anos de escolaridade, um importante determinante da desigualdade de rendimentos, cresceu juntamente com a média para a coorte nascida ate o final da década de quarenta, atingiu um máximo para os grupos nascidos ao redor de 1950 e declinou para os as coortes mais recentes.

A relação entre as mencionadas tendências na distribuição da escolaridade e na desigualdađie de rendimentos é analisada mediante decomposição de uma equação padrão de salários à la capital humano. A variância decrescente referente aos anos de escolaridade implica, por si só, redução na desigualdade de rendimentos para as coortes mais recentes. Essa relação é alterada, entretanto, por mudanças nos rendimentos resultantes da escolaridade e por outras fontes de desigualdade de remuneração. A comparação dos perfis de idade e da desigualdade para 1976, 1982 e 1985, mostra que a desigualdade dos rendimentos no Brasil aumentou durante o citado período. Através da decomposição realizada mostramos que a contribuição da escolaridade foi no sentido de melhorar a distribuição de 1976 a 1985, com redução tanto na variância como nos retornos do processo de escolaridade. Entretanto, outras fontes de desigualdade cresceram em magnitude suficientemente grande para compensar as mudanças favoráveis na distribuição da escolaridade e na relação entre escolaridade e rendimentos. 


\section{Mudanças na distribuiçāo da escolarizaçāo.}

Inicialmente apresentamos as tendências da distribuição da variável anos completos de escolarização, agrupando os nascidos do sexo masculino entre 1925 e $1963^{1}$ em coortes definidas por intervalos trianuais. Nossa análise baseia-se na Pesquisa Nacional por Amostra de Domicílio (PNAD) de 1985, levantamento domiciliar anual realizado pelo Instituto Brasileiro de Geografia e Estatística (IBGE), agência responsável pelos censos brasileiros. Dividimos a amostra em grupos etários com intervalos de três anos para analisar as tendências na escolaridade ocorridas nas décadas recentes. Dado o amplo tamanho da amostra da PNAD, a análise dos grupos etários em intervalos de três anos permitiu-nos, ao mesmo tempo, obter amostras grandes e um grau relativamente bom de informações sobre o perfil das coortes. ${ }^{2}$ A amostra, com representatividade nacional, foi utilizada para inferir a história da escolaridade dos grupos nascidos entre 1925 e 1963 . O procedimento será apropriado se a amostra representar verdadeiramente a população do país e se os efeitos diferenciais da mortalidade e migração para os diferentes grupos de escolaridade forem desprezíveis para as coortes analisadas.

A Tabela 1 apresenta as estatísticas que descrevem a distribuição dos anos completados de escolaridade entre os grupos etários trianuais na PNAD de $1985 .^{3}$ O aumento persistente no nível médio de anos de escolaridade completados pode ser observado na coluna (4) da Tabela 1 e no Gráfico 1 . Embora o nivel de escolaridade permaneça baixo, o número médio de anos completos de escolaridade para os homens cresceu persistentemente ao longo do tempo, duplicando no período das quatro décadas incluidas aqui. O número médio de anos de escolarização elevou-se de

\footnotetext{
${ }^{1}$ Como estamos interessados na distribuição de renda assim como de escolaridade, seguimos a maioria da literatura nas áreas de escolaridade e desigualdade e nos restringimos ao estudo dos homens, evitando os temas mais difíceis em oferta de trabalho que envolvem a análise do ciclo de vida dos rendimentos femininos.

${ }^{2}$ Temos uma amostra de mais de 100.000 homens nas coortes analisadas, sendo que o menor grupo etário contém mais de 2.800 observaçōes.

${ }^{3}$ Os resultados apresentados usam a ponderação amostral fornecida pelo IBGE de modo a gerar uma amostra representativa de indivíduos para a população Brasileira. Os tamanhos amostrais relatados referem-se ao número de observaçōes não ponderadas. Todas as estatísticas foram calculadas usando os pesos amostrais. O algoritmo para construir as variáveis para anos de escolaridade completos estão disponíveis, podendo ser obtidos com os autores.
} 


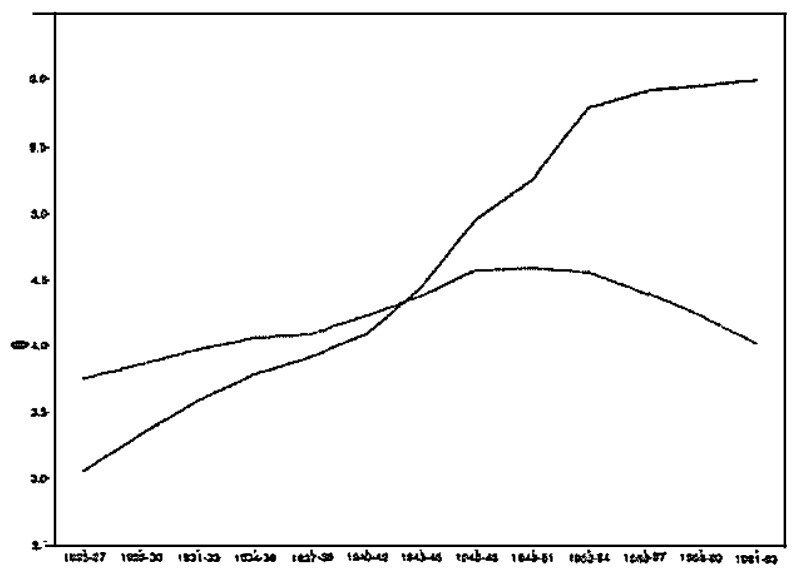

(eixo vertical: Anos de escolaridade completa)

(eixo horizontal: Coortes de nascimento)

Anos de escolaridade completa, média e

Desvio padrão coortes de nascimento trianuais,

Homens brasileiros, PNAD de 1985.

\section{Gráfico 1.}

três anos, para o grupo de nascidos entre 1925 e 1927, para seis anos, referentes à coorte de 1961-63. O crescimento mais rápido da média deu-se para os grupos nascidos entre 1940 e 1954, onde a nıaior parte freqüentou a escola durante a década de cinqüenta e início de sessenta. O ritmo de crescimento da média parece ter começado a cair com os nascidos entre 1955 e 1957, embora a escolaridade incompleta para os grupos mais jóvens possa explicar essa redução.

A variância nos anos de escolaridade para o conjunto de coortes do sexo masculino é apresentada na Coluna 5 da Tabela 1 . A variância será analisad a extensivamente adiante, pois mostrar-se-á variável fundamental na decomposição da desigualdade de rendimentos. Por conveniência de apresentação, o desvio padrão dos anos de escolaridade é apresentado no Gráfico 1, pois é medido em unidades comparáveis com a média. Como demonstram a Tabel a e o Gráfico, o desvio padrão cresce para as coortes nascidas nos intervalos 1925-27 até 1949-51, declinando em seguida para os grupos das décadas de cinqüenta e sessenta. 
Tabela 1.

Anos completos de escolaridade para

grupos etários em intervalos

trianuais, brasileiros do sexo

masculino, PNAD de 1985

\begin{tabular}{|c|c|c|c|c|c|c|c|c|c|}
\hline \multirow{2}{*}{$\begin{array}{l}\text { Grupo } \\
\text { Etário }\end{array}$} & \multirow{2}{*}{$\begin{array}{c}\text { Coorte } \\
\text { de } \\
\text { Nasc. }\end{array}$} & \multirow{2}{*}{$\begin{array}{c}\text { Tamanho } \\
\text { da } \\
\text { Amostra }\end{array}$} & \multirow[t]{2}{*}{ Média } & \multirow[t]{2}{*}{ Var. } & \multirow{2}{*}{$\begin{array}{c}\text { Coef. } \\
\text { de } \\
\text { Var. }\end{array}$} & \multicolumn{4}{|c|}{$\begin{array}{c}\text { Percentagem de Anos } \\
\text { Completos }\end{array}$} \\
\hline & & & & & & 0 & $4+$ & $8+$ & $11+$ \\
\hline (1) & (2) & (3) & (4) & (5) & (6) & (7) & (8) & (9) & (10) \\
\hline $22-24$ & $1961-63$ & & 5,98 & 16,08 & 0,67 & 11,8 & 72,2 & 37,8 & 20,0 \\
\hline $25 \cdot 27$ & $1958-60$ & 13 & 5,93 & 17,80 & 0,71 & 12,2 & 70,9 & 36,4 & 20,9 \\
\hline $28-30$ & $1955-57$ & 11734 & 5,89 & 19,33 & 0,75 & 13,2 & 70,2 & 34,9 & 21,8 \\
\hline $31-33$ & 1952 & 106 & 5,77 & 20,66 & 0,79 & 14,2 & 67,0 & 32,9 & 21,6 \\
\hline $34-36$ & t949-51 & & & & 0,87 & 17,9 & & 3,4 & 18,8 \\
\hline $37-39$ & $1946-48$ & 8386 & 4,95 & 20,84 & 0,92 & 19,1 & 57,8 & 25,4 & 16,9 \\
\hline $40-42$ & $1943-45$ & 763 & 4,43 & 19,12 & 0,99 & 23,4 & 52,5 & 21,6 & 14,3 \\
\hline $43-45$ & $1940-42$ & 7 & 4,08 & & 1,03 & 25,2 & 48,2 & 18,9 & 12,5 \\
\hline $46-48$ & $1937-39$ & 6109 & 3,92 & 16,75 & 1,04 & 26,5 & 47,6 & 17,7 & 11,3 \\
\hline $49-51$ & $1934-36$ & 5588 & 3,78 & 16,52 & 1,08 & 28,2 & 46,1 & 16,7 & 10,8 \\
\hline $52-54$ & $1931-33$ & 4942 & 3,58 & 15,70 & 1,11 & 30,7 & 44,3 & 15,5 & 10,0 \\
\hline $55-57$ & $1928-30$ & 4590 & 3,32 & 14,84 & 1,16 & 33,7 & 40,9 & 13,9 & 8,6 \\
\hline $58-60$ & $1925-27$ & 4099 & 3,05 & 14,03 & 1,23 & 37,3 & 37,7 & 12,3 & 7,7 \\
\hline $22-60$ & $1925-63$ & 107431 & 4,98 & 19,11 & 0,88 & 19,6 & 59,3 & 27,2 & 16,8 \\
\hline
\end{tabular}

O valor máximo atingido pela variância nos anos de escolaridade foi apontado anteriormente por Lam e Levinson (1990), utilizando dados da PNAD de 1976. Esse resultado é mais firmemente aqui estabelecido mediante as informações de 1985, pois o grupo nascido no intervalo 1949-51 tinha 34-36 anos na época deste levantamento, idade suficiente para que a escolaridade tenha sido virtualmente completa. ${ }^{4} \mathrm{O}$ auge da variância da escolaridade será uma característica permanente da distribuição desta variável durante o período de vida da coorte nascida entre 1949 e 1951, tendo importantes implicações para a distribuição de rendimentos.

O Gráfico 1 mostra uma importante caracteristica da mu-

\footnotetext{
${ }^{4}$ Se a escolaridade é incompleta para as coortes mais jovens, a variância dos anos de escolaridade será subestimada para estas cooltes. A comparaçāo das mesmas coortes, em outros anos, sugere que o máximo na variância de escolaridade nāo é, simplesmente, um artifício deste efeito, como será discutido a seguir.
} 
dança na desigualdade da escolaridade ajustada pela média. Embora o desvio padrão referente aos anos de escolaridade cresça ao longo do tempo para as coortes nascidas entre 1925 e 1948, não o faz tão rapidamente como a média, como deveria acontecer caso tivesse ocorrido um aumento proporcional da escolaridade para a população como um todo. Isto implica que o coeficiente de variação, uma medida padrão de desigualdade que independe da média, declinou persistentemente durante as quatro décadas analisadas. O coeficiente de variação (o desvio padrão dividido pela média) é apresentado na Coluna 6 da Tabela 1 . Por esta medida, a desigualdade na escolaridade dos brasileiros de sexo masculino decresceu persistentemente nas décadas recentes. Enquanto a média da escolaridade dobrou, o coeficiente de variação reduziu-se quase à metade. ${ }^{5}$

Média crescente e coeficiente de variação declinante não são uma característica exclusiva do caso brasileiro. Psacharopoulos e Arriagada (1986) apresentam, para um grande número de paises, estimativas da proporção da força de trabalho com diferentes niveis de escolaridade e da média da escolaridade. Para vinte países, os dados apresentados abrangem mais de 20 países e referem-se a vários anos. Ram (1990) utiliza dados agrupados para estimar o desvio padrão de cada população. Embora os resultados obtidos não possam ser comparados perfeitamente com os aqui encontrados, uma vez que baseiam-se em distribuições categóricas de freqüência e não em anos de escolaridade completos, além de dizerem respeito à forca de trabalho como um todo, é possível comparar mudanças nas médias, desvio padrão e coeficientes de variação para intervalos de dez a vinte anos. Entre os vinte países estudados, o Brasil apresenta um dos maiores incrementos na média de escolaridade, tanto em termos absolutos como relativos, com crescimento um pouco mais lento que a Coréia, embora mais rápido que a maior parte dos paises asiáticos e da América Latina. Para todos os paises, a média de escolaridade cresceu mais rapidamente que o desvio padrão, implicando reduções, em todos os casos, da

\footnotetext{
${ }^{5}$ Lam e Sedlacek (1990), usando os mesmos dados, documentam um padrāo semelhante para as mulheres brasileiras. A escolaridade média para mulheres, crescea de 2,7 anos para as coortes de 1925-27, finalmente ultrapassando a dos homens até atingir um nível de 6,3 anos para a coorte 1961-63. O máximo na variancia da escolaridade para as mulheres é atingido no coorte 1952-54, um pouco mais tarde do que o dos homens.
} 
desigualdade na escolaridade ajustada pela média. ${ }^{6}$

Um importante componente do crescimento da média de escolaridade no Brasil é o declínio da proporção de homens com zero anos de escolaridade completada, apresentada na Coluna 7 da Tabela 1. Esta percentagem declinou regularmente de 37, para o grupo nascido entre 1925-27, chegando a menos de 12 para a coorte do periodo 1961-63. As Colunas 8, 9 e 10 da Tabela 1 apresentam outro importante aspecto da distribuição acumulada. A proporção de homens com pelo menos quatro anos de escolaridade cresceu de $38 \%$ para $73 \%$, a proporção com pelo menos oito anos (primeiro grau completo) passou de $12 \%$ para $38 \%$ e a proporção com pelo menos onze anos (segundo grau completo) pulou de $8 \%$ para $20 \%$. O fato de que a proporção de homens com segundo grau parece ter declinado para as coortes mais recentes sugere que a escolaridade incompleta pode complicar os resultados para as coortes mais jovens, questão discutida mais à frente.

Uma descrição mais completa das mudanças na distribuição da escolaridade é obtida comparando-se a distribuição de freqüência dos anos de escolaridade completos para três coortes específicas: os nascidos entre 1925-27, o grupo com mais idade na Tabela 1; a coorte com a mais alta variância de escolaridade, correspondente ao intervalo de nascimento 1949-51; e o grupo mais jovem da Tabela 1, com nascimento entre 1961 e 1963. O Gráfico 2 apresenta a distribuição de freqüência de anos de escolaridade para os grupos mencionados. As densidades de freqüência apresentam formas bastante similares, com picos para zero, quatro, oito e onze anos, consistentes com o término dos diversos níveis do sistema brasileiro de educação. A mais forte diferença entre o grupo mais velho e o mais jovem é a acentuada queda na pro-

\footnotetext{
${ }^{6}$ Ram (1990) usa, como medida de desigualdade de escolaridade, o desvio padrāo, rejeitando medidas com ajustamento na média, como o coeficiente de. variaçāo, porque, entre outras razōes, estas medidas nāo sāo zero quando a média o é. O critério de Ram é peculiar, já que a maioria das medidas de desigualdade, que satisfazem os axiomas padrões, violarão este critério. Usamos a variância da escolaridade nas nossas decomposiçōes da desigualdade de rendimentos, a seguir, mas seguindo a literatura convencional em desigualdade de renda, que faz diferença conceitual entre mudanças na média e mudanças na dispersão ajustada pela média, usamos o termo "desigualdade" quando nos referimos a medidas que são independentes da média. Também seguimos trabalhos anteriores em desigualdade de rendimentos, como o clássico estudo de Jencks (1972), que usam o coeficiente de variaçāo como uma medida de desigualdade de escolaridade.
} 


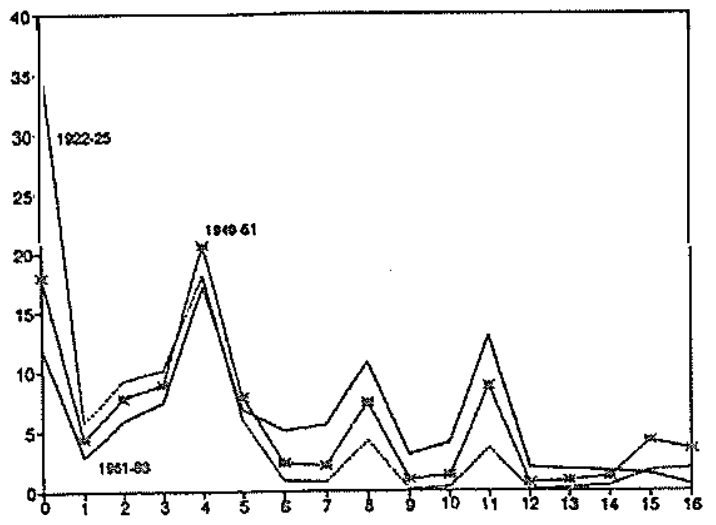

(eixo vertical: Freqüência, percentagem) (eixo horizontal: Anos de escolaridade completa)

Distribuição de ffreqüência, anos de escolaridade completa 1925-27, 1949-51

e 1961-63 coortes de nascimento, homens brasileiros, PNAD de 1985

Gráfico 2.

porção de zero anos de escolaridade. A proporção de homens com exatamente quatro anos de escolaridade é notavelmente constante entre as três coortes. Contudo, este resultado não deve ser interpretado como indicação de inércia na distribuição da escolaridade. O Gráfico 2 demonstra que todos os niveis de escolaridade inferiores a quatro anos têm se tornado menos freqüentes ao longo do tempo, enquanto que niveis de escolaridade superiores a quatro anos têm tido maior ocorrência, com os quatro anos sendo, aproximadamente, o ponto onde as densidades de freqüência se cruzam.

A distribuição acumulada da escolaridade implícita nas densidades de freqüência do Gráfico 2, e apresentada nas quatro últimas colunas da Tabela 1, sugere fortemente a dominância estocástica de primeira ordem da distribuição ao longo do tempo, condição que prevaleceria se as distribuições acumuladas não se interceptassem. Uma maneira interessante de interpretar estas distribuições é supor a utilidade como função dos anos de escolaridade: $U(S)$. Dada uma função utilidade, de bem estar social, $\int U(S) f(S) d S$, 
dominância estocástica de primeira ordem implica bem estar social mais elevado para qualquer função $U(S)$, crescente em $S$. Portanto, dominância estocástica de primeira ordem implicaria que a distribuição da escolaridade no Brasil, sem qualquer dúvida, melhorou ao longo do tempo. $\dot{E}$, até mesmo, mais forte que dominância estocástica de segunda ordem, que implicaria maior bem estar social para qualquer função côncava $U(S)$ (veja Atkinson, 1970; Kakwani,1980; Shorrocks, 1983; e Lam, 1988). Como mostram as quatro últimas colunas da Tabela 1, pode-se afirmar quase com total certeza a ocorrência de melhoria na distribuição da escolaridade pelo critério de dominância estocástica de primeira ordem para cada grupo, comparativamente ao seu predecessor.

A distribuição acumulada permite apontar, sem ambigüidade, a existência de melhoria na distribuição da escolaridade entre coortes de brasileiros do sexo masculino, utilizando-se o mesmo critério de dominância estocástica empregado para comparar distribuições de renda não ajustadas pela média (Shorrocks,1983). Grande parte desta melhoria decorre de aumentos na média. Ao comparar-se distribuições de renda, é procedimento usual considerar medidas de dispersão ajustadas pela média que independem do nivel médio de renda. Da mesma forma, é interessante perguntar se desigualdade de escolaridade, independentemente da média, tem declinado no Brasil. Já vimos que uma medida de desigualdade padrão, o coeficiente de variação, declina de fato e persistentemente durante o periodo considerado. Uma comparação mais completa pode ser feita analisando-se curvas de Lorenz para a distribuição da escolaridade, definidas - analogamente às curvas de Lorenz para renda - como a proporção acumulada de anos de escolaridade em relação à proporção acumulada da população.

O Gráfico 3 apresenta as curvas de Lorenz para anos de escolaridade referentes às três coortes analisadas acima. O gráfico mostra, sem nenhuma dúvida, que as curvas de Lorenz para anos. de escolaridade deslocam-se para cima ao longo do tempo, refletindo uma clara melhoria de igualdade na escolaridade. Por exemplo, os $50 \%$ menos educados da população do grupo de nascidos entre $1925-27$ possuiam menos de $8 \%$ do total de anos de escolaridade, em referência ao próprio grupo. Para a coorte do intervalo correspondente a 1961-63, os cinqüenta menos educados do grupo tinham $23 \%$ do total de anos de escolaridade. A curva de Lorenz indica que a parcela dos anos de escolaridade referente àqueles que se encontram no piso da distribuição cresceu sustentadamente ao 


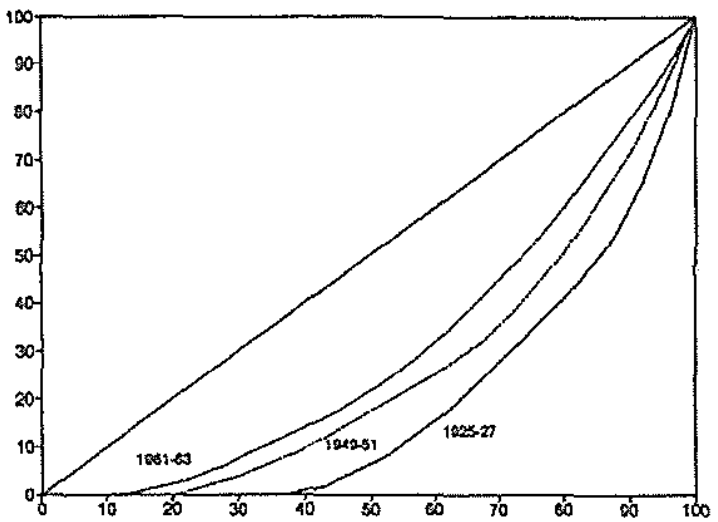

(eixo vertical: Percentagem acumulada de escolaridade) (eixo horizontal: Percentagem acumulada da população)

Curvas de Lorenz, Anos de escolaridade completa 1925-27, 1949-51 e 1961-63 Coortes de nascimento, Homens brasileiros, PNAD de 1985

Gráfico 3.

longo do tempo.

Análise das curvas de Lorenz para distribuição de anos de escolaridade não é usual, mas decorre naturalmente da análise da desigualdade da escolaridade. ${ }^{7}$ Para interpretar estas curvas de Lorenz, considere a relação entre as curvas de Lorenz para a distribuição de anos de escolaridade e as curvas de Lorenz para a distribuição de renda. A literatura sobre as curvas de Lorenz e bem estar social nos mostra que a dominância de Lorenz sobre a renda implica um nivel de bem estar social mais alto para qualquer função utilidade côncava, abstraindo-se de mudanças na média (Atkinson, 1987; Shorrocks, 1983). Passando-se da escolaridade para utilidade através da renda, $U[Y(S)]$, a dominância de Lorenz em relação aos anos de escolaridade implica, claramente, um nivel de bem estar social mais alto, mesmo sem aumentos

\footnotetext{
${ }^{7}$ Jencks (1972), de fato, apresenta qual o significado das curvas de Lorenz para escolaridade entre coortes de nascimento no seu clássico estudo da desigualdade de escolaridade e desigualdade de rendimentos para os Estados Ufxidos.
} 
na média de escolaridade, se a utilidade for uma função côncava da escolaridade. As condições suficientes (mas não necessárias) para que a utilidade seja uma função côncava da escolaridade são: (i) que a renda seja uma função côncava da escolaridade e (ii) que a utilidade seja uma função côncava da renda. Embora estas condições pareçam plausíveis à primeira vista, deve-se lembrar que na representação mais usual, a equação log linear convencional de rendimentos da teoria do capital humano: $\ln Y=a+\beta S$, a renda é, na verdade, uma função convexa da escolaridade. Uma decorrência desta relação funcional é poder-se observar claramente uma distribuição de escolaridade mais igual, como indicada pelas curvas de Lorenz, juntamente com uma inequivocamente menos igual distribuição de renda, como mostram as curvas de Lorenz para rendimentos, mesmo se a escolaridade determinar inteiramente os rendimentos. Será visto adiante que a evidente melhoria, no Brasil, na desigualdade da escolaridade ajustada pela média nao implica, necessariamente, melhoria na distrlbuição de rendimentos durante o periodo em que a variância nos anos de escolaridade era crescente.

\section{Implicações para a distribuição de renda.}

$\dot{E}$ de se esperar que as mudanças na distribuição da escolaridade mostradas acima acarretem importantes implicações para a distribuição dos rendimentos. A relação entre escolaridade e distribuição de renda tem sido enfatizada na literatura sobre desigualdade de renda. Previsões baseadas em um modelo da teoria do capital humano foram realizadas por Becker e Chiswick (1966) e Chiswick (1971), incluindo entre elas a afirmação de que redução na desigualdade de escolaridade levaria a reduções na desigualdade de rendimentos. Testes empíricos baseados em dados para vários países revelam evidências contraditórias. ${ }^{8}$ Winegarden (1970), a. partir de dados para 32 países, encontrou uma associação negativa entre desigualdade de renda e escolaridade média, com a variância de escolaridade positivamente associada à desigualdade de renda. Ram (1984), utilizando informações para 28 paises, obteve apenas efeitos marginalmente significativos, com a variância da escolaridade tendo um efeito equalizador. Como apontado por Knight e Sabot (1987), o crescimento dos níveis médios de educação pode,

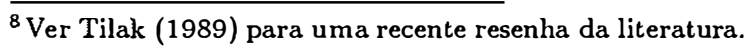

\section{4}


em princípio, causar aumento ou redução na desigualdade de rendimentos, dependendo das mudanças específicas ocorridas nos diferentes níveis de escolaridade e na realação entre escolaridade e rendimentos. Como veremos adiante, no caso da equação de rendimentos da teoria do capital humano, é possível gerar, simultaneamente, reduções na desigualdade de escolaridade e elevações na desigualdade de rendimentos.

Uma forma natural de estabelecer a relação entre a distribuição de escolaridade e a de rendimentos, e definí-la no contexto de uma simples e convencional equação de rendimentos

$$
\ln Y_{i}=\alpha+\beta S_{i}+u_{i}
$$

onde $\ln Y_{i}$ é o logaritmo natural do rendimento do trabalho do $i$-ésimo indivíduo, $S_{i}$ é o número de anos de escolaridade do $i$ ésinıo indivíduo e $u_{i}$ é o resíduo, representando todos os outros determinantes do rendimento auferido pelo $i$-ésimo indivíduo. $\mathrm{Na}$ equação de rendimentos não consideramos a experiência do indivíduo porque para grupos etários definidos por intervalos reduzidos, uma proxy padrão para a experiência adquirida terá correlaşão quase perfeita com anos de escolaridade. A equação (1) pode ser interpretada simplesmente como uma relação funcional empírica apropriada, ou pode ser motivada por um modelo de rendimentos da teoria do capital humano, como em Mincer (1974). Qualquer que seja a alternativa, a especificação da equação (1) na forma semi-logarítmica convencional proporciona uma decomposição analiticamente simples da variância do log dos rendimentos, uma medida padrão de desigualdade. ${ }^{9}$

Supondo que $\alpha$ e $\beta$ representam constantes da população, a variância do $\log$ do redimento $V(\ln Y)$ decorrente da equação (1) é

$$
V(\ln Y)=\beta^{2} V(S)+V(u)+2 \beta C(S, u)
$$

onde $V(S)$ é a variância nos anos de escolaridade, $V(u)$ é a variância dos componentes dos rendimentos não correlacionados

\footnotetext{
${ }^{9}$ Alérn do fato que o uso da variância no log dos rendimentos segue, naturahnente, da equação dos rendimentos na teoria do capital humano, ela é também uma medida de desigualdade bastante usada. Esta medida satisfaz axiomas padrōes para medidas de desigualdade e na classe das medidas convencionais dá mais peso relativo à cauda inferior da distribuição [ver Kakwani (1980) e Atkinson (1970)].
} 
aos anos de escolaridade, e $C(S, u)$ é a covariância entre anos de escolaridade e as variáveis omitidas na equação de rendimentos.

De acordo com a equação (2), a variância dos anos de escolaridade é um determinante fundamental da variância do $\log$ dos rendimentos. Se a escolaridade for não correlacionada com os outros determinantes não incluídos na equação simples de rendimentos (1), então, mudanças na variância de escolaridade levam diretamente a mudanças na desigualdade de rendimentos por um fator que é o quadrado do retorno da escolaridade. Se os retornos da escolaridade e a "variância residual" forem constantes, então, a desigualdade de rendimentos, medida pelo log da variância, é simplesmente uma função linear da variância dos anos de escolaridade.

A equação (2) implica que é possível ocorrer o crescimento da desigualdade de rendimentos ao mesmo tempo em que decresce a desigualdade de escolaridade. Segundo a equação, desigualdade de rendimentos é apenas função da variância dos anos de escolaridade sem efeito independente da escolaridade média. Entretanto, a desigualdade na escolaridade, como definida convencionalmente, é função tanto da variância como da média. Se a variância na escolaridade crescer enquanto cai o seu coeficiente de variação, observaremos, então, ao mesmo tempo, um aumento na desigualdade de rendimentos e uma redução na desigualdade de escolaridade. Esta é, exatamente, a situação das coortes de brasileiros do sexo masculino nascidos entre 1925 e 1951. Embora neste período a desigualdade de escolaridade, aferida por todas as medidas de desigualdade ajustadas pela média, tenha declinado para coortes consecutivas, deveríamos esperar um crescimento da desigualdade de rendimentos devido ao aumento na variância da escolaridade. Para os grupos nascidos depois de 1951, tanto a desigualdade na escolaridade ajustada pela média como a variância da escolaridade declinaram, implicando desigualdade de rendimentos decrescente.

Utilizaremos a equação (1) como referência para análise da relação entre a distribuição de escolaridade e de rendimentos. Adotaremos a interpretação da equação (1) fornecida ria do capital humano, embora reconhecendo que as estimativas de $\beta$ possam capturar outros efeitos além dos retornos privados da escolaridade. Correlações entre escolaridade e variáveis omitidas afetarão não somente a interpretação do coeficiente relativo à escolaridade, como implica, também, que o último termo da equação (2) não pode ser ignorado na decomposição da variância

\section{6}


do $\log$ dos rendimentos. Assim mudanças na distribuição da escolaridade podem afetar a variância do log dos rendimentos não somente através da "variância explicada", $\beta^{2} V(S)$, mas também através da variância "não explicada".

Embora nosso objetivo principal não diga respeito a estimativas dos retornos da escolaridade per se, a qualidade da especificação da equação de rendimentos (1) afeta, sem dúvida, a interpretação dos nossos resultados. Se, por exemplo, os retornos da escolaridade forem não lineares, então, a variância do log dos rendimentos dependerá de momentos da distribuição da escolaridade mais altos que a variância. Se um termo quadrático fizer parte da equação de rendimentos, então, não será rigorosamente correto interpretar a "variância explicada" como se a estimação da equação (1) capturasse todos os efeitos da distribuição da escolaridade. Enquanto a variância explicada captura todos os efeitos sobre a renda correlacionados com a escolaridade, não irá capturar efeitos de ordem mais alta que apresentam-se, por exemplo, como correlações entre renda e o quadrado da escolaridade. Utilizamos a especificação da equação (2) porque fornece uma decomposição analítica simples da desigualdade especificamente decorrente da idade. O simples acréscimo de um termo quadrático para escolaridade, por exemplo, resulta em dois componentes adicionais para a decomposição, um deles dependendo da "kurtose" da distribuição da escolaridade e o outro da assimetria . Embora tal decomposição possa ser interessante, entendemos que a decomposição linear captura os componentes mais importantes da relação entre desigualdade de escolaridade e de rendimentos. ${ }^{10}$

Uma hipótese adicional na nossa interpretação da decomposição na equação (2) e a existência de retornos constantes para a escolaridade no interior de cada coorte. Omitimos, portanto, um dos determinantes da desigualdade de rendimentos na decomposição teórica de Becker e Chiswick (1966) e Chiswick (1971), a variância dos retornos da escolaridade. Dada a variância do retorno da escolaridade, um nivel médio de escolaridade crescente tenderá a aumentar a desigualdade de rendimentos, mesmo que a variância em termos de anos de escolaridade seja constante. Nossos resultados devem ser qualificados, também, pela já bastante conhecida advertência de que o coeficiente referente à escolari-

${ }^{10}$ Como será demostrado a seguir, na discussāo da robustez dos nossos resultados, a especificaçāo linear simples ajusta bem os grupos etários trianuais que Eoram usados nas regressōes. 
dade inclui o efeito de muitas variáveis omitidas e correlacionadas com escolaridade. Afirma-se freqüentemente que no Brasil, assim como em muitos países em desenvolvimento, altos níveis de escolaridade encontram-se mais concentrados entre as crianças de famílias ricas que nos Estados Unidos, de tal forma que a escolaridade representa uma proxy para posição social e ligações entre famílias. Identificar o significado preciso da forte associação entre escolaridade e rendimentos no Brasil é tarefa que vai além do escopo deste artigo, embora deva-se observar que a utilização estrita da teoria do capital humano na interpretação dos resultados deva ser feita com cautela. ${ }^{11}$

\section{Equações de rendimentos e a decomposição da desi- gualdade de rendimentos, 1985.}

Com o objetivo de analisar a relação entre a distribuição da escolaridade e de rendimentos para as coortes discutidas anteriormente, apresentamos as estimativas das equações de rendimentos (1) para os grupos etários com intervalos trianuais de brasileiros do sexo masculino, com rendimento mensal positivo registrado na PNAD de 1985. Estas regressões, 'juntamente com as estatísticas descritivas para rendimentos, são apresentadas na Tabela $2 .{ }^{12}$

Para analisar graficamente os resultados da Tabela 2 podemos usar como unidade de referência o ano de nascimento ou a idade. Embora a escolha seja, em um certo nivel, apenas uma questão de ler a tabela de cima para baixo ou de baixo para cima, chama atenção para problemas conceituais mais importantes relativos à análise da desigualdade de rendimentos entre grupos etários. A média e o desvio padrão da escolaridade, colocados no Gráfico 1

\footnotetext{
${ }^{11}$ Reconhecemos que não estamos levando em consideração muitos determinantes, históricos e institucionais da desigualdade, particularmente em relação às grandes variaçōes regionais na desigualdade do Brasil. Repetimos nossa. análise para regiōes separadas do Brasil e para amostra de populaçōes urbanas e rurais. Estes resultados são apresentados no trabalho de Lam e Levison (1989), que é sumariado, brevemente, a seguir.

12 Ao se mudar a amostra de todos os homens brasileiros para a amostra de homens brasileiros com rendimentos do trabalho positivos, há mudanças na distribuição de escolaridade. As diferenças nas duas amostras dependem dos grupos etários. Para faixas mais jovens, a amostra de homens que trabalham, tem uma média de escolaridade um pouco maior do que a do total dos homens. No entanto, as diferenças são pequenas e não implicam mudanças significativas nos padrōes da média e variância da escolaridade entre as coortes documentadas a seguir.
} 


\section{Tabela 2.}

Rendimentos mensais do trabalho por idade estatísticas descritivas

e equação de rendimentos específica por grupos etários homens

brasileiros com rendimentos positivos, PNAD de 1985

\begin{tabular}{|c|c|c|c|c|c|c|c|c|c|c|}
\hline \multirow{2}{*}{$\begin{array}{l}\text { Grupo } \\
\text { Etário }\end{array}$} & \multirow{2}{*}{$\begin{array}{c}\text { Coorte } \\
\text { de } \\
\text { Nasc. }\end{array}$} & \multirow{2}{*}{$\begin{array}{l}\text { Tamanho } \\
\text { da } \\
\text { Amostra }\end{array}$} & \multirow{2}{*}{$\begin{array}{l}\text { Média } \\
\text { dos } \\
\text { Rend. } \\
\left(x 10^{-3}\right)\end{array}$} & \multirow{2}{*}{\multicolumn{2}{|c|}{$\begin{array}{l}\text { Média Var. } \\
\text { dos log. } \\
\text { Rend. Rend. }\end{array}$}} & \multicolumn{5}{|c|}{$\begin{array}{l}\text { Equação de Rendimentos } \\
\text { especifica da Idade }\end{array}$} \\
\hline & & & & & & $\hat{\beta}$ & D.P. & $R^{2}$ & $V(u)$ & $\hat{\rho}^{2} V(S)$ \\
\hline (1) & (2) & (3) & (4) & (5) & (6) & (7) & (8) & (9) & (10) & (11) \\
\hline $22-24$ & $1961-63$ & 11689 & 801 & 13,2 & 0,638 & 0,110 & 0,0016 & 0,296 & 0,449 & 0,189 \\
\hline $25-27$ & $1958-60$ & 11763 & 1080 & 13, & 0,773 & 30,1 & 0,0 & 0,366 & 0,490 & 0,283 \\
\hline $28-30$ & & & & & & & & & 514 & \\
\hline $31-3$ & $1952-54$ & 10022 & 1572 & 13,75 & 0,987 & 0,147 & 0,0016 & 0,455 & 0,538 & 0,449 \\
\hline $34-36$ & $1949-51$ & 9152 & 1666 & 13,76 & 66 & 0,155 & 0,0017 & 0,478 & 0,556 & 0,509 \\
\hline $37-39$ & $1946-48$ & 7919 & 1781 & 13,78 & 26 & 0,158 & 0,0019 & 0,469 & 0,598 & 0,528 \\
\hline $40-42$ & & 7157 & & & 03 & 0,163 & 21 & 0,469 & 0,585 & 0,518 \\
\hline $43-45$ & $1940-42$ & 6565 & 1639 & 13,70 & 95 & 0,164 & 0,0023 & 0,445 & 0,608 & 0,487 \\
\hline $46-48$ & $1937-39$ & 5497 & 1664 & 13,67 & 14 & 0,164 & 0,0026 & 0,416 & 0,651 & 0,463 \\
\hline $49-51$ & $1934-36$ & 4788 & 1584 & 13,64 & 122 & 0,164 & 0,0029 & 0,401 & 0,673 & 0,450 \\
\hline $52-54$ & $1931-33$ & 3982 & 1542 & 13,59 & 097 & 0,165 & 0,0033 & 0,388 & 0,672 & 0,425 \\
\hline $55-57$ & $1928-30$ & 3463 & 1352 & 13,47 & 107 & 0,160 & 0,0038 & 0,343 & 0,727 & 0,380 \\
\hline $58-60$ & $1925-27$ & 72841 & 1334 & 13,381 & ,156 & 0,171 & 0,0045 & 0,341 & 0,762 & 0,394 \\
\hline $22-60$ & $1925-63$ & 395791 & 1424 & 13,610 &, 998 & 0,138 & 0,0006 & 0,370 & 0,629 & 0,370 \\
\hline
\end{tabular}

Not a: "Rendimentos" refere-se ao total dos rendimentos, em cruzeiros, de todos js empregos, no mês anterior a pesquisa (Setembro de 1985). Valores na coluna 1, média dos rendimentos, estāo divididos p6r 1000. Resultados de regressāo zorrespondem aos M.Q.O. da regressão $\ln Y_{i}=\alpha+\beta S_{i}$, para cada grupo etário.

conno função do ano de nascimento, podem ser adequadamente interpretados como atributos das coortes. Ou seja, variam com a idade para adultos em uma cross section particular devido a mudancas na escolaridade ao longo do tempo, e não como decorrência de uma relação fundamental entre escolaridade e idade. Os rendimentos do trabalho, por outro lado, variam sistematicamente em relação à idade e podem, portanto, ser entendidos como fun ção da idade e não da coorte. Apresentamos os componentes dos rendimentos como função da idade nos gráficos que se seguem, 
reconhecendo, porém, que vizualiza-se simultaneamente os efeitos da "idade" e da "coorte", com a importância relativa dos dois componentes variando de gráfico para gráfico.

O Gráfico 4 apresenta a variância do log dos rendimentos para cada grupo etário, juntamente com os componentes explicado e não explicado desta variável, decorrentes das nossas estimativas da equação (1) para cada grupo. A forma do perfil etário associado à desigualdade tem importantes implicações para a relação entre a composição etária da população e a distribuição de renda como um todo. ${ }^{13}$ Como mostra o Gráfico 4 e Coluna 6 da Tabela 2 , a variância do log dos rendimentos para os brasileiros do sexo masculino cresce com forte inclinação para os grupo etários de 22-24 anos até o grupo de 37-39 anos, tornando-se, então, relativamente constante para os grupos mais velhos. A relação entre idade e desigualdade apresentada no Gráfico 4 é similar ao padrão encontrado por Langoni (1973) para grupos de brasileiros do sexo masculino, utilizando os dados do censo de 70. 0 padrão difere significativamente da relação entre idade e desigualdade de rendimentos nos Estados Unidos: Mincer (1974), Schultz (1975) e Smith e Welch (1979) encontraram, todos, perfis de desigualdade por idade em forma de $U$, em estimativas

os americanos do sexo masculino. ${ }^{14}$ Como discutido em maiores detalhes em Lam e Levinson (1990), o formato desse perfil de desigualdade com referência à idade é o resultado da interação entre o perfil da variância da escolaridade das coortes, mudanças nos retornos da escolaridade por idade e do perfil etário da variância residual.

O crescimento na desigualdade dos grupos etários de 22-24 anos até 37-39, apresentado no Gráfico 4, é consistente com as previsões baseadas no perfil da variância da escolaridade das coortes documentado acima. O aumento da desigualdade com a idade sugere que a variância decrescente da escolaridade entre coortes está provocando o declínio na desigualdade dos rendimentos para as coortes mais recentes. A explicação para o perfil etário da desigualdade é, contudo, certamente mais complexa. Como veremos adiante, mudanças na variância da escolaridade entre coortes

\footnotetext{
${ }^{13}$ Veja, por exemplo, Paglin (1975), Morley (1981) e Lam (1984).

${ }^{14} \mathrm{O}$ perfil da desigualdade de rendimentos por experiência, foi também estimado por um número de pesquisadores. Ver Lam e Levison (1990) para uma discussāo da literatura e comparação dos perfis de desigualdade por idade e experiência no Brasil e U.S..
} 


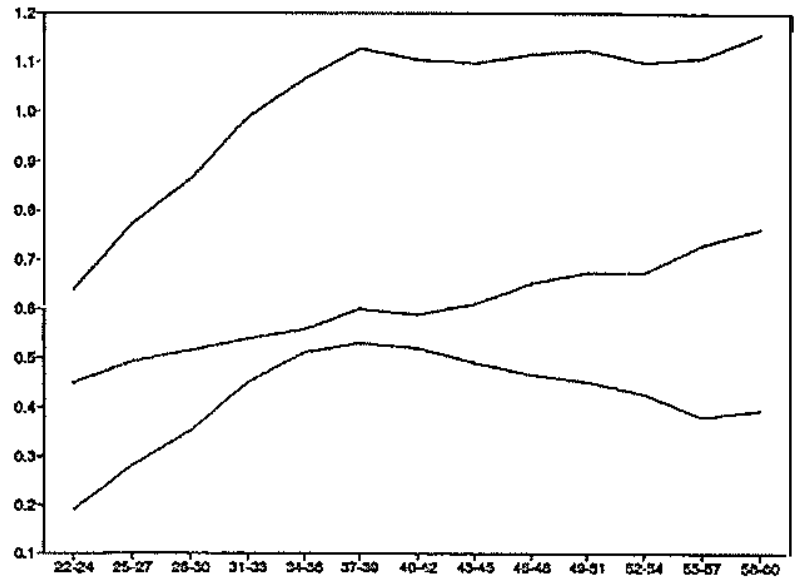

(eixo vertical: Variância do log. da Escolaridade)

(eixo horizontal: Grupos Etários)

Desigualdade de Rendimentos, Grupos Etários

Trianuais Variância Total do Log dos Rendimentos, Variância Explicada e Variância Residual, Homens com Rendimentos Positivos, Brasil, PNAD de 1985

\section{Gráfico 4.}

explicam apenas parte da relação entre idade e desigualdade no Brasil.

Retornando à equação (2), observamos que o retorno da escolaridade ${ }^{15}$ constitui importante determinante da variância do log dos rendimentos. A Coluna 7 da Tabela 2 indica que os retornos estimados

como função da idade, crescendo acentuadamente para os grupos de 22-24 anos até 37-39 anos, permanecendo depois relativamente constante para os grupos etários mais velhos. ${ }^{16}$ Tanto o fator idade como coorte devem desempenhar um papel importante na

\footnotetext{
${ }^{15}$ No total, a estimativa dos retornos à escolaridade para homens com idade entre 22 e 60 foi de 0,138 para 1985. Este resultado está próximo ao de Senna (1976), cujas estimativas foram de 0,125 e 0,127 para os homens brasileiros, usand a mesma função simples de rendimentos e a amostra do Ministério do Trabalho para o ano de 1970.

${ }^{16}$ Os desvios padrões sāo, consistentenente, muito pequenos, e as estimativas par a os retornos à escolaridade sāo, sem exceçāo, significantes a um nível de um por cento.
} 
determinação deste perfil. Knight e Sabot (1981), por exemplo, sugerem que níveis mais altos de escolaridade para as coortes mais jovens podem explicar o freqüentemente observado aumento dos retornos da escolaridade com o aumento da idade. Comparações com estimativas das PNADs de 1976 e 1982, apresentadas abaixo, revelam um perfil etário com formato bastante similar, sugerindo, entretanto, a existência de alguma relação sistematicamente persistente entre idade e retornos da escolaridade no Brasil.

"A variância explicada", $\beta^{2} V(S)$, da desigualdade de rendimentos é resultado da combinação do retorno dos rendimentos com a variância nos anos de escolaridade. A Coluna 10 da Tabela 2 e o Gráfico 4 apresentam a variância das regressões de rendimentos para os grupos etários em intervalos trianuais. A variância explicada é mais alta para homens entre 37-39 anos, representando coortes nascidas entre 1946 e 1948. Os dois elementos da variância explicada comportam-se muito diferentemente em relação ao grau em que resultam do fator "idade" ou "coorte". A variância da escolaridade é fundamentalmente uma caracteristica das coortes, permanecendo constante quando a coorte ultrapassa aproximadamente os 25 anos. Como mostrado acima, a variância da escolaridade é mais alta para a coorte do período 1949-51, correspondendo ao grupo de 34-36 anos em 1985. Argumentos teóricos podem ser apresentados quanto aos efeitos da idade e da coorte nos retornos da escolaridade, especialmente em uma população experimentando rápidas mudanças nos niveis de escolaridade. Qualquer que seja a explicação para o padrão etário em relação aos retornos da escolaridade, ele interage com o padrão da coorte quanto à variância da escolaridade para produzir a relação entre idade e "variância explicada" apresentada no Gráfico 4.

A variância residual (não explicada) nas equações de rendimentos por grupos etários é apresentada na Coluna 10 da Tabela 2 e no Gráfico 4. A variância residual cresce de modo razoavelmente persistente a partir do grupo de 22-24 anos, passando de .45 , na coorte mais jovem, e atingindo .76 na coorte mais velha. A variância residual inclui a variância resultante de investimentos em capital humano realizados após o periodo de escolaridade, tais como on the job training e experiência, como enfatizou Mincer (1974). Pode também incluir efeitos decorrentes de mudanças na escolaridade, uma vez que foram omitidas da equação (1) log linear simples de rendimentos variáveis correlacionadas com a escolaridade. De qualquer forma, de uma perspectiva pragmática, 
é uma importante explicação do fato que, para os brasileiros do sexo masculino, a desigualdade cresce com a idade.

\section{Mudanças na desigualdade de rendimentos, 1976-1982- 1985.}

A melhoria na distribuição da escolaridade acima descrita levou a melhoria na distribuição dos rendimentos? Na presente seção comparamos a distribuição de rendimentos para 1976, 1982 e 1985 a fim de encontrar as mudanças na desigualdade de rendimentos ocorridas neste periodo e identificar o papel da escolaridade nestas mudanças. ${ }^{17}$ Existe um importante problema de identificação quando se compara o mesmo grupo etário em diferentes periodos de tempo. Se comparamos o mesmo grupo etário em diferentes periodos, coortes diferentes estarão sendo comparadas. Se comparamos a mesma coorte em diferentes periodos, estaremos observando a coorte em diferentes pontos do seu ciclo de vida. Assim, quando controlamos a idade, os efeitos referentes à coorte aparecerão como efeitos decorrentes do periodo, e quando controlamos a coorte, os efeitos da idade parecerão como resultantes do periodo. Os Gráficos 5 e 6 ilustram o problema ao comparar a distribuição de renda no Brasil ao longo do tempo.

O Gráfico 5 apresenta a variancia do $\log$ dos rendimentos para os grupos etários com intervalos trianuais, para brasileiros do sexo masculino, tendo como base as PNADs de 1976, 1982 e 1985. O Gráfico mostra que a desigualdade é maior para todos os grupos em 1985, relativamente a 1982, e mais alta em 1985 que em 1976 para todos os grupos etários acima de 34 anos. O Gráfico 6 apresenta os mesmos dados como função da data de nascimento da coorte e não da idade. ${ }^{18}$ Todas coortes de nascimento tem mais alta desigualdade de rendimentos em 1985 que em 1982 e 1976. Todas coortes de nascimento, exceto a do intervalo 1925-27, tem mais alta desigualdade de rendimento em 1982 que em 1976.

Apesar da marcante melhoria na distribuição da escolaridade, a evidência de que a desigualdade de rendimentos cresceu, de 1976 a 1985, para todas as coortes de nascimento e para a maioria dos grupos etários mostra que a distribuição dos rendimentos piorou.

\footnotetext{
${ }^{17}$ Ao se fazer esta comparaçāo, estamos assumindo que as pesquisas PNAD, para este três anos, são, consistentemente, representativas da população nacional. A validade desta hipótese é discutida a seguir.

${ }^{18}$ Os gráficos das coortes incluem somente observaçōes para grupos etários com idade superior a 21 anos.
} 


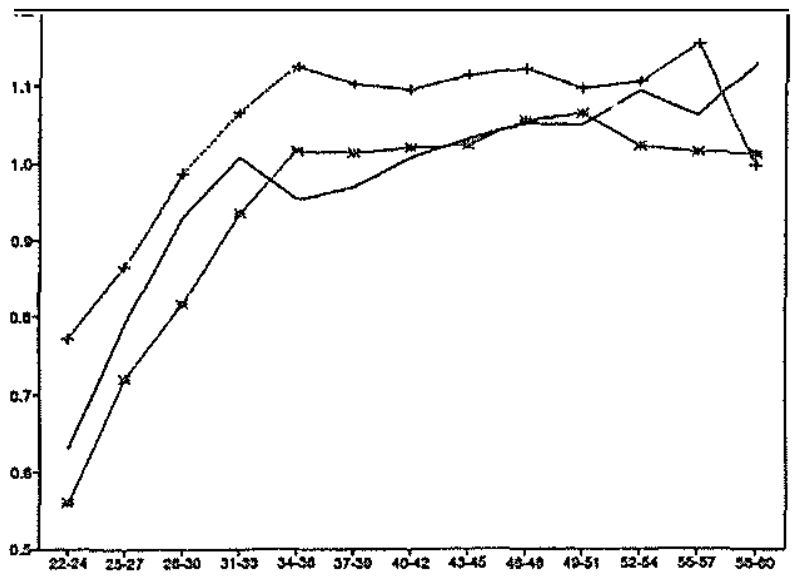

(eixo vertical: Variância do log dos rendimentos)

(eixo horizontal: Grupos etários)

Variância do log dos rendimentos para grupos

Etários trianuais homens com rendimentos

Positivos, PNAD de 1976, 1982 e 1985

\section{Gráfico 5.}

Qual a explicação para esse perturbador aumento na desigualdade e como reconciliá-lo com a melhoria na distribuição da escolaridade? Mais uma vez, a decomposição da desigualdade de rendimentos é esclarecedora.

\section{Mudanças}

Examinando o Gráfico 5, qual a explicação para o crescimento da desigualdade para todos os grupos etários de 1982 a 1985 e para os grupos mais velhos entre 1976 e 1985? Uma importante parte da explicação é o efeito coorte para os grupos mais velhos, como resultado de uma distribuição de escolaridade variável ao longo do tempo. Este efeito coorte é completamente independente de mudanças nas condições econômicas, e portanto não deve ser atribuido a diferenças na economia brasileira em 1976, 1982 e 1985. Um exemplo esclarecedor é dado no Gráfico 6 pelo grupo etário entre 37 e 39 anos, grupo este que apresenta grandes mudanças na desigualdade entre os três períodos. Este grupo corresponde à coorte de nascimento no período 1946-48 em 1985, à coorte 1943- 


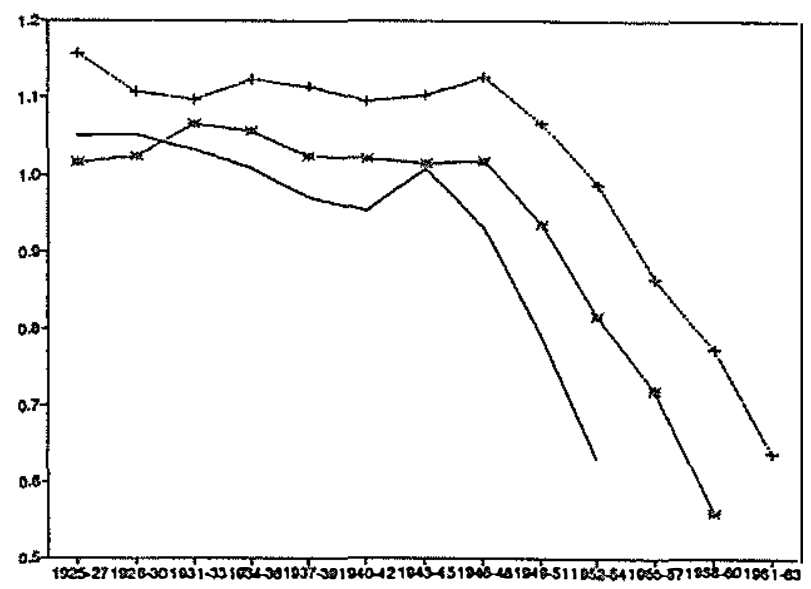

(eixo vertical: Variância do log dos rendimentos)

(eixo horizontal: Coortes de nascimento)

Variância do log dos rendimentos para

Coortes de nascimento trianuais homens com Rendimentos Positivos, PNAD de 1976, 1982 e 1985

\section{Gráfico 6.}

45 em 1982 e a do intervalo 1937-39 em 1976. Revendo a Tabela 1, observamos que essas três coortes apresentam variância nos anos de escolaridade bastante diferentes. As maiores diferenças na desigualdade de rendimentos para este grupo etário nos três períodos são atribuídas às mudanças na variância da escolaridade ao longo do tempo, sem implicar necessariamente em qualquer ligação com as condições econômicas dos três períodos.

Vemos, portanto, como as mudanças na distribuição da escolaridade no Brasil pode afetar a distribuição de renda ao longo do tempo. No tocante aos três levantamentos sendo aqui comparados, o efeito coorte está aumentando a desigualdade entre os grupos mais velhos e reduzindo-a nos grupos mais jovens. Para as idades mais avançadas, a coorte de nascimento, a uma dada idade em 1985, apresentava uma mais alta variância de escolaridade que a coorte de nascimento a essa mesma idade em 1982 . O resultado é verdadeiro para coortes nascidas antes do pico na variância da escolaridade. Para as idades menos avançadas, a coorte de nasci- 
mento a uma certa idade em 1985, deveria ter uma variância de escolaridade menor que a coorte de nascimento a esta idade em 1982.

O problema referente à possibilidade de incorretas interpretações do efeito coorte, como apresentado no Gráfico 5, pode ser resolvido comparando-se coortes, e não grupos etários, ao longo do tempo. O Gráfìco 6 compara desigualdade de rendimentos em 1976, 1982 e 1985 para as mesmas coortes de nascimento. Uma vez que a variância de escolaridade permanece constante ao longo do tempo para uma dada coorte, o aumento na desigualdade para coortes de nascimento apresentado no Gráfico 6 não pode ser atribuído a mudanças na variância da escolaridade. A comparação entre coortes, apresentada no Gráfico 5, leva, entretanto, a outra fonte de inferência potencialmente incorreta. Para uma dada coorte, as mudanças na desigualdade dos rendimentos ao longo do tempo serão afetadas ou pelas varições nos retornos da escolaridade ou pela variância residual como função da idade. Pelos resultados apresentados acima, sabemos que no Brasil, tanto os retornos da escolaridade como a variância residual variam significativamemte com a idade. Assim sendo, examinamos o comportamento de cada uma dessas variáveis em 1976, 1982 e 1985, para investigar o papel que ténham possivelmente desempenhado na explicação do aumento da desigualdade de rendimentos no Brasil durante este periodo.

\section{Mudanças nos Retornos da Escolaridade}

Como destacado acima, um dos fatores críticos que afetam as mudanças na desigualdade entre periodos é a mudança nos retornos da escolaridade. Langoni (1973), enfatizou o papel das mudanças nos retornos da escolaridade ao explicar o aparente aumento da desigualdade no Brasil durante as décadas de sessenta e setenta. Langoni argumentou que a desigualdade cresceu neste período em parte como decorrência do aumento nos retornos da escolaridade, resultado do quasi-rent relativo ao capital humano provocada pelo rápido (e possivelmente inesperado) crescimento econômico.

O Gráfico 7 apresenta os retornos da escolaridade em 1976, 1982 e 1985 para grupos de idade em intervalos trianuais, obtidos por estimativas das equações de rendimento especificadas como em (1). O gráfico mostra que, ao longo do tempo, os retornos da escolaridade cairam para todos os grupos de idade, resultado 


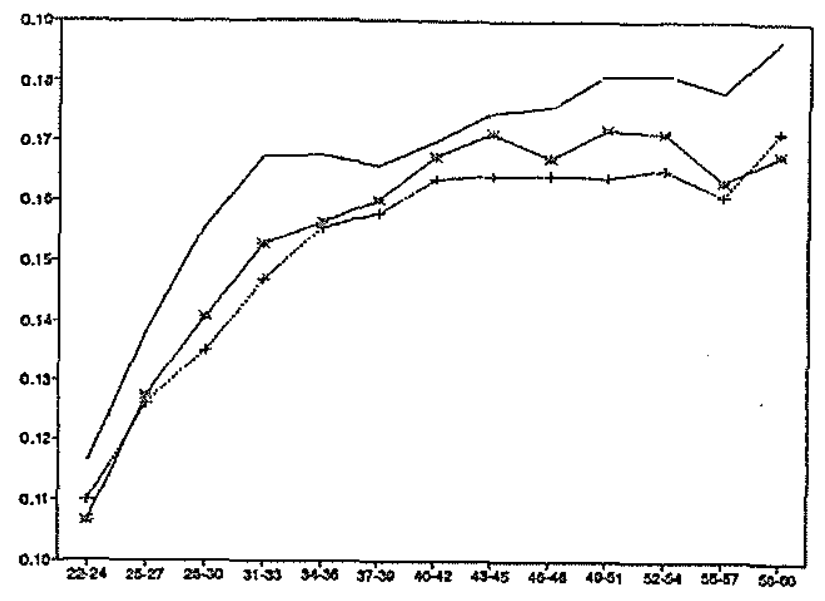

(eixo vertical: Retornos a escolaridade)

(eixo horizontal: Grupos etários)

Retornos a Escolaridade estimados para grupos

Etários trianuais homens com rendimentos

Positivos, PNAD de 1976, 1982 e 1985

\section{Gráfico 7.}

que, por si só, implica declínio na desigualdade de rendimentos para todos os grupos no período. Em relação aos grupos mais velhos, o declínio nos returnos da escolaridade tende a compensar o aumento na desigualdade resultante do fato que as coortes com variância mais altas na escolaridade ingressaram nestes grupos etários em 1985. Para os grupos mais jovens, o declínio nos rendimentos da escolaridade reforça a redução na desigualdade, decorrência de que as coortes com variâncias da escolaridade mais baixas ingressaram nestes grupos em 1985.

Durante este período, é notável o declínio no retorno da escolaridade em cada grupo etário no Brasil, embora não se tenha certeza se representa tendência de longo prazo ou não. Tendências no nível geral do retorno da escolaridade será um importante determinante da tendência de longo prazo da desigualdade de rendimentos no Brasil. Da mesma forma que em outros países em desenvolvimento, as estimativas de retorno da escolaridade no Brasil têm sido muito mais altas que as obtidas para os Estados Unidos e outras economias industrializadas (ver Psacharopoulos, 1981, 
e Schultz, 1988). Os resultados encontrados por Lam e Levinson, por exemplo, indicam que os retornos da escolaridade para os homens brasileiros são aproximadamente $5 \%$ superiores aos resultados referentes aos americanos do sexo masculino, para quase todos os grupos de idade.

O declínio no retorno da escolaridade no Brasil para todos os grupos etários, entre 1976 e 1985, pode indicar que o crescimento do nivel médio de escolaridade no Brasil está levando ao desaparecimento de altas rents, relativas ao que, no passado, corespondia ao relativamente escasso capital humano do país. Se a afirmação for verdadeira, a conseqüência deverá ser a redução da desigualdade de rendimento ao longo do tempo, à medida em que coortes com melhor nivel educacional ingressem no mercado de trabalho. Seja o declínio no retorno da escolaridade, mostrado no Gráfico 7, uma tendência permanente ou o resultado de condições cíclicas de curto prazo da economia brasileira para os três anos analisados ${ }^{19}$, permanece verdadeira a afirmação de que este declínio possui um efeito equalizador no período considerado.

\section{Variância Residual}

Uma vez que nossas estimativas indicam que no periodo compreendido entre 1976 e 1985 ocorreu, simultaneamente, decréscimo na variância da escolaridade e no retorno da escolaridade, o aumento generalizado da desigualdade entre 1976 e 1985, apresentado nos Gráficos 5 e 6, não pode ser atribuido a escolaridade, ao menos no que diz respeito a decomposição da equação (1). A contribuição da escolaridade neste periodo foi melhorar a distribuição de renda. Decorre que mudanças na variância residual, a variância do componente dos rendimentos não correlacionada com escolaridade, deve desempenhar um importante papel. A Tabela A do Apêndice detalha os elementos da decomposição da desigualdade para 1976 e 1982, comparativamente à análise feita pura 1985. A comparação da variância residual para os grupos etários e para as coortes basearla nas estimativas de rendimentos da equação, (2) para 1976 , 1982 e 1985, mostra que a variância residual é mais alta em 1985, para todos os grupos etários e coortes, que ein 1976 e 1982. As mudanças na variância residual são !nenos conclusivas. Embora entre 1976 e 1982 tenha ocorrido um pequeno acréscimo

\footnotetext{
${ }^{19} \mathrm{Em} 1976$ as condiçōes econômicas estavam declinando após os นuus de arescimento de 1968-'i4; o vale da recessāo foi em 1982-83 e em 1985 as condiçōes eram de retomada de crescimento.
} 
de desigualdade para a maior parte das coortes, isso é resultado, principalmente, da forte tendência de crescimento da variância residual com o passar da idade. De fato, com exceção de apenas um, todos os grupos apresentaram variância residual mais baixa em 1982 que em 1976.

O crescimento generalizado na variância residual entre 1976 e 1985, tanto para grupos etários como para coortes, é suficientemente grande para superar o efeito equalizador da variância decrescente nos anos de escolaridade e retornos descrescentes da escolaridade. Este é um resultado perturbador, pois significa que o Brasil não conseguiu obter a melhoria na distribuição de renda que deveria ter decocorrido das mudanças na distribuição da escolaridade e de seus retornos. Por outro lado, na medida em que a variância residual, tal como aqui definida ( i. e., a variância dos componentes do rendimento não correlacionados com escolaridade), esteja sendo impulsionada por efeitos cíclicos de curto prazo, incluindo talvez a taxa de inflação, cresce a confiança de que o aumento da desigualdade entre 1976 a 1985 possa ser atribuido a variância residual. Os efeitos equalizadores da distribuição de escolaridade mais favorável representam uma mudança fundamental nos determinantes da desigualdade de rendimentos no Brasil. Este componente da desigualdade persistirá por décadas no Brasil. O fato de que bem sucedidas coortes de brasileiros do sexo masculino tenham, continuadamente, variância nos anos de escolaridade mais baixa, levará por si só a uma melhoria na distribuição de renda no futuro. A medida em que as coortes com variâncias na escolaridade mais altas, aquelas nascidas ao redor de 1950, percorrerem a distribuição de idade e forem substituídas por coortes mais recentes, a desigualdade de renda no Brasil deverá apresentar o tipo de melhoria que, no momento, observa-se apenas para um conjunto reduzido de grupos etários.

\section{Robustez dos resultados.}

Os resultados apresentados acima são sensiveis a um certo número de hipóteses. Se a PNAD de 1985 não representar corretamente a população brasileira, então, a análise cross section baseada em coortes será não confiável, afetando nossas conclusões a respeito da distribuição da escolaridade ao longo do tempo. Se algum homem nas coortes mais jovens não tiver completado sua escolaridade à época do levantamento de 1985, o declínio na 
variância da escolaridade pode ser uma conclusão incorreta, derivada do processo de escolaridade não concluído. Se as PNADs de 1976, 1982 e 1985 não forem consistentes entre si, nossas conclusões sobre mudanças nos retornos da escolaridade ao longo do tempo podem não se sustentar. Especificação incorreta da equação de rendimentos constitui outra preocupação, uma vez que pode afetar a validade das estimativas dos retornos da escolaridade e a interpretação da nossa decomposição. Na presente seção apresentamos uma breve análise destas questões.

Comparações da distribuição da escolaridade para as mesmas coortes por amostras de anos diferentes fornecem evidências tanto sobre a consistência das PNADs quanto aos efeitos potenciais de uma escolaridade não concluida para os jovens do sexo masculino. As amostras de 1976, 1982 e 1985 apresentam estimativas totalmente consistentes da média da escolaridade entre coortes, uma vez atingida a metade da década dos trinta por essas mesmas coortes. Discrepâncias entre escolaridade média para a mesma coorte em 1982 e 1985 são caracteristicamente menores que um décimo de ano, magnitude equivalente a um terço até um meio da mudança na média da escolaridade de um grupo etário trianual para o seguinte. A amostra de 1976 não é tão consistente, com médias da ordem de 0.3 a 0.4 anos abaixo as de 1985 , para quase todas as coortes.

Comparações da variância da escolaridade sugerem que a escolaridade não concluída contribui, de fato, para uma variância decrescente nas coortes mais jovens. Contudo, o pico observado da variância parece ser real. A coorte de 1946-48 apresenta a mais alta variância, tanto na amostra de 1976 como na de 1982 , com as coortes de 1946-48 e 1949-51 passando, na amostra de 1985, como descrito pelo Gráfico 1, por um pico mais achatado. Concluímos das nossas comparações que as amostras de 1982 e 1985 são altamente consistentes, sugerindo que a hipótese de que apresentam uma amostra consistente da população brasileira é bastante plausivel. Estamos menos confiantes quanto à cumparabilidade com o levantamento de 1976, embora ele forneca uma descrição semelhante do padrão básico, tanto da média como da variância da escolaridade. Par'ece claro que tem havido, ao menos, achatamento substancial da variância dos anos de escolaridade entre coortes, com evidência razoavelmente segura de que a variância tem declinado para coortes nascidas desde o início da década de cinqüenta. 
Para testar a robustez da nossa hipótese relativa à especificação linear da equação de rendimentos, utilizamos os dados de 1985 para estimar especificações mais fiexiveis. Para a maior parte dos grupos etários, o tamanho das nossas amostras é suficientemente grande para permitir-nos estimar regressões utilizando dezoito variáveis dummy para os anos de escolaridade dos indivíduos. Além de testar a robustez de nossa hipótese de linearidade, essas estimativas sao interessantes por si mesmas, pela descrição que fazem da relação entre escolaridade e rendimentos no Brasil. O Gráfico 8 apresenta os resultados para três grupos etários representativos. Os coeficientes mostram o log dos rendimentos para cada nivel de escolaridade, relativamente aos homens com zeros anos de escolaridade. Dado o pequeno tamanho das células e m algumas categorias de anos de escolaridade, estas estimativas não paramétricas para diferentes grupos etários são surpreendentemente regulares e sugerem uma notável relação linear entre o $\log$ dos rendimentos e escolaridade. Como evidência da plausibilidade da especificação linear, comparamos $\circ R^{2}$ para regressões de rendimentos utilizando especlficação linear, quadrática e não paramétrica com dezoito dummy. Para o grupo etário de 34-36 anos, por exemplo, esses $R^{2}$ são $.478, .479$ e .488 , respectivamente. A utilização de especificações mais fiexiveis resulta em melhorias no poder de explicação igualmente modestas para todos os grupos etários. ${ }^{20}$

Como teste final da sensibilidade dos nossos resultados, consideramos variacões regionais nos padrões acima apresentados. Disparidades entre regiões geográficas e entre áreas urbanas e rurais são, freqüentemente, de grande importância nos estudos empíricos de desigualdade no Brasil. ${ }^{21}$ Para responder questões quanto ao nível geral de desigualdade no Bŕasil, nossa amostra com representatividade nacional apresenta a dimensão adequada de análise. Análise por regiões e, na verdade, um estudo de desigualdades intra região, enquanto que desejamos examinar tanto a variância n a distribuição de rendimentos entre regiões romo intra região.

\footnotetext{
${ }^{20}$ Estimativas do retorno da escolaridade podem ser viesadas, devido a uma variedade de razōes, tais como omissāo de experiência ou habilidade familiar. Behrman e Wolfe (1984), por exemplo, concluem através da evidência obtida de grupos familiares na Nicarágua que estimativas dos retornos à escolaridade sāo, significantemente exageradas quando nāo se controla por características de experiência dos parentes. Entretanto, nāo há razāo para se esperar uma relaçāo sistemática entre estes viéses potenciais e idade ou coortes.

21 Ver, por exemplo, Almeida Reis e Barros (1989).
} 


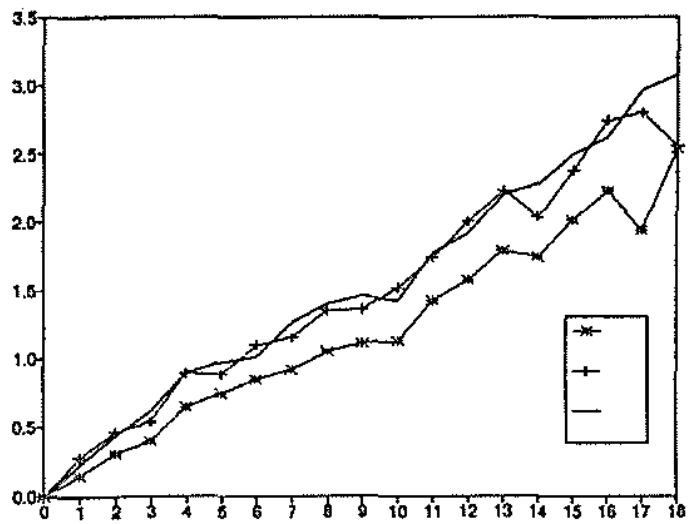

(eixo vertical: Logaritmo dos rendimentos relativos)

(eixo horizontal: anos de escolaridade completa) Regressões por M.Q.O., usando anos de escolaridade completa, logaritmo dos rendimentos relativos aos homens com nenhum ano de escolaridade completa, grupos etários trianuais, homens brasileiros com rendimentos positivos, PNAD de 1985.

\section{Gráfico 8.}

Uma amostra nacional também evita o sério problema das migracões internas, que, sabidamente, variam sistematicamente com a idade, educação e rendimento. Grupos etários em uma região podem levar a uma representação pobre, por exemplo, da história da escolaridade dos homens nascidos na região.

De qualquer forma, é interessante verificar se o padrão que descrevemos acima se sustenta para as distintas regiões. Utilizando o PNAD de 1985 geramos resultados equivalentes à Tabela 1 e 2 para duas regiões do Brasil bastante diferentes, o Nordeste e o Sudeste, com estratificações adicionais para localização urbanorural. ${ }^{22}$ Encontramos mudanças da escolaridade no interior da região Nordeste e Sudeste similares àquelas observadas para o Brasil como um todo. Observamos para as duas regiōes, aumento persistente na escolaridade média e declínio, também persistente,

\footnotetext{
22 Ver, Lam e Levison (1989) para uma análise detalhada destas comparaçōes regionais.
} 
na desigualdade ajustada pela média, ao longo do tempo e para as áreas urbana e rural. Encontramos para o Sudeste como um todo e para sua região urbana, um pico da variância da escolaridade similar ao do Brasil como um todo. As áreas urbanas do Nordeste e o Nordeste como um todo, apresentam um padrão de variância crescente, atingindo um pico e depois caindo, embora o pico ocorra para coortes um pouco mais jovens que para o Brasil como um todo. As áreas rurais em ambas regiões apresentam variância da escolaridade bem mais baixa, que tende a subir ao longo das quatro décadas. Estimativas de equacões para idades específicas e para a localização urbano rural indicam um perfil de desigualdade por idade fortemente similar ao do Brasil como um todo. Intra região encontramos o mesmo padrão de retornos da escolaridade crescentes com a idade, como visto para o Brasil como um todo no Gráfico 7. Encontramos, também, o mesmo pacirẽo de variancia residual crescente cum a idade intra região e para as áreas urbana e rural. No conjuntı, os padrões do perfil de desigualdade dos rendimeritos por idade para todo o Brasıl parecem bastante robustos entre regiões, apesar das grandes diferenças nos níveis gerais de escolaridade e rendimentos nestas regiões.

\section{Conclusões.}

Análise de grupos etários trianuais da PNDA de 1985 indica que as coortes de homens brasileiros nascidos nas quatro décadas entre 1925 e 1963 apresentaram um crescimento continuado no nivel rnédio de escolaridade, com a média duplicando das coortes mais velhas para os mais novos. O crescimento na média estava associarlo ao declínio continuado da desigualdade de escolaridade. $\mathrm{O}$ coeficiente de variação dos anos de escolaridade decresceu para todos as coortes consecutivas, decrescendo por quase $50 \%$ entre cs coortes mais velhos e mais novos. As curvas de Lorenz para os anos de escolaridade denonstram um declínio inequívoco para a desigualdade em escolaridade ajustadas pela média. A variância dos anos de escolaridade, um determinante crítico na desigualdade dos rendimentos, cresc $\leq$ para as primeiras duas décadas do período, atingindo um máximo com a coorte de 1949-51 e decreszeu para todos as coortes consecutivas.

Estimativas das equações de rendimentıss individuais para grupos etários trianuais em 1985 indicam que mudanças na distribuiçân ủe escolaridade no Brasil devem por si próprias ter melhorado a distribuição dos rendimentos do trabalho no Brasil, 
começando como os coortes nascidas no início dos anos 50. A desigualdade dos rendimentos decresceu, drasticamente, entre os coortes 1946-48 e 1961-63, um padrão que é previsto pelo declínio na variância dos anos de escolaridade no período. Entretanto, a decomposição das equações de rendimento mostram que existem dois outros fatores que são importantes para explicar est.e declínio. Ambos, os retornos a escolaridade e a variância residual, são maiores para coortes mais velhos, fazendo com que a desigualdade cresça mais rapidamente com a idade (i.e. decrescendo com coortes de nascimento). Estes dois efeitos fortalecem os efeitos de mudanças na variância da escolaridade na desigualdade de rendimentos.

Comparações dos perfis de desigualdade de idade e coortes para 1976, 1982 e 1985, mostram que a desigualdade de rendimentos no Brasil cresceu ao longo deste período, apesar das mudanças benéficas na desigualdade de escolaridade. Nossa decomposição indica que a contribuição da escolaridade foi, de fato, para melhorar a distribuição no período 1976 a 1985, com redução tanto na variância da escolaridade como nos retornos da escolaridade. Embora o crescimento, para o mesmo periodo, na variância do componente de rendimentos, que é não correlacionado com escolaridade, seja perturbador, acreditamos que nossos resultados, no que diz respeito ao componente de rendimentos da desigualdade, proporciona razões otimistas sobre o futuro da desigualdade de rendimentos no Brasil. Enquanto a variância residual pode ser sensivel a condições econômicas de curto-prazo, as substanciais melhorias na distribuição de escolaridade, que documentamos, representam mudanças fundamentais na determinação da desigualdade de rendimentos no Brasil. Nossos resultados sugerem que mudanças na distribuição de escolaridade no Brasil em décadas recentes, têm tido efeitos benéficos na distribuição de renda e, que devem perdurar por décadas. O declínio na variância da escolaridade que começou para os homens nascidos por volta do ano de 1950 , implica que as novas coortes que entram no mercado de trabalho, devem apresentar uma desigualdade de rendimentos menor em todas as idades, com as melhorias passadas na distribuição de escolaridade tendo um efeito igualador crescente na desigualdade de rendimentos total, à medida que as coortes de nascimentos posteriores a 1950 se tornam uma proporção crescente da força de trabalho.

A evidência apresentada anteriormente sugere que a recente 
experiência do Brasil, tanto no acréscimo do nível médio de escolaridade quanto na redução da desigualdade da escolaridade, não é única entre os paises em desenvolvimento. Isto sugere que os nossos resultados possam ter implicações para outros países. Na medida em que a expansão do sistema educacional em outros países em desenvolvimento reduzir a variância na escolaridade, como parece estar acontecendo no Brasil, deverão ocorrer melhorias na desigualdade de rendimentos. Se, além disto, houver um declínio no retorno da escolaridade, como também parece ter acontecido no Brasil, haverá uma melhoria adicional na distribuicão de rendimentos. Infelizmente, a recente experiência do Brasil também demonstrou que, mesmo havendo melhoria substancial no componente escolaridade da desigualdade dos rendimentos, esta não garante um declínio na desigualdade como um todo. Espera-se que estes sejam efeitos cíclicos de curto-prazo, que serão dominados no longo-prazo por melhorias estruturais na distribuição da escolaridade.

\section{Referências}

Almeida dos Reis, J.G. e R.P. de Barros. Income inequality and the Distribution of Education: Regional Differences in Inequality. Rio de Janeiro, IPEA-INPES, 1989.

Atkinson, A.B. On the Measurement of Inequality. Journal of Economic Theory, 2: 244-263, 1970.

Becker, G.S. e B.R. Chiswick. Education and the Distribution of Earningb. American Economic Review, 56 (2): 358-69, 1966.

Behrman, J.R. e B.L. Wolfe. The Socioeconomic Impact of Schooling in a Developing Country. Review of Economics and Statistics, 66 (2): 296-303, 1984.

Chiswick, B. Earningb. Inequality and Economic Development. Quarterly Journal of Economics, 85 (1):21-39.

Fishlow, A. Brazilian Size Distribution of Income. American Economic Revicw, 62 (2):391-410, 1972.

Jencks, C. et. al. Inequality: A Reassessment of the Effect of Family and Schooling in America. New York, Basic, 1972.

Kakwani, N.C. Income Inequality and Poverty: Methods of Estimation and Policy Applications. Oxford University Press, 1980.

Knight, J.B. e R.H. Sabot. The Returns to Education: Increasing with Experince or Decreasing with Expansion. Oxford 
Bulletin of Economics and Statistics, 43:51-71, 1981.

Knight, J.B. e R.H. Sabot. Education Expansion, Government Policy, and Wage Compression. Journal of Development Economics, 26 (2): 201-221, 1987.

Lam, D.. The Variance of Population Characteristics in Stable Populations, with Applications to the Distribution of Income. Population Studies, 38:117-27, 1984.

Lam, D. Lorenz. Curves, Inequality and Social Welfare under Changing Populations Composition. Journal of Policy Modeling, Abril: 1988.

Lam, D. e D. Levison. Declining Inequality in Schooling in Brazil and Its Effects on Inequality in Earnings, Population Studies Center. Research Report, $\mathrm{n}$ - 89-170. Universidade de Michigan, 1989.

Lam, D. e D. Levison. Age, Experience and Schooling: Decomposing Earnings Inequality in the U.S. and Brazil. Pesquisa $e$ Planejamento Econômico a sair, 1990.

Lam, D. e G. Sedlacek. Women Education, Female Labor Supply, and Fertility Decline in Brazil. University of Michigan, 1990.

Langoni, C.G. Distribuição da Renda e Desenvolvimento Econômico do Brasil. Rio dé Janeiro, Editora Expressão e Cultura, 1973.

Langoni, C.G.. Income Distribution and Economic Development: The Brazilian Case. em Michael D. Intriligator (ed.) North Holland: Amsterdam Frontiers of Quantitative Economics, B 587-606, 1977.

Marin, A. e G. Psacharopoulos. Schooling and Income Distribution. Review of Economics and Statistics, 58 (3): 332-38, 1976.

Mincer, J. Schooling, Experience and Earnings. NBER New York. 1974.

Morley, S. The Effect of Changes in the Population on several Measures of Income Distribution. American Economic Review, 71 (3): 285-94, 1981.

Paglin, M. The Measurement and Trend of Inequality: A Basic Revision. American Economic Review, 65:598-609, 1975.

Psacharopoulos, G. e A.M. Arriagada. The Educational Composition of the Labor Force: An International Comparison. International Labour Review, 125 (5): 561-574: 1986.

Ram, R. Population Increase, Economic Growth, Educational Inequality, and Income Distribution. Journal of Development 
Economics, 14: 419-428, 1984.

Ram, R. Educational Expansion and Schooling Inequality: International Evidence and Some Implications. Review of Economics and Statistics, 72 (2): 266-273, 1990.

Schultz, T.P. Education Investments and Returns. em Chenery Hollis e T.N. Srinivasan (eds). Handbook of Development Economics, New York Elsevier Science, 1988.

Schultz, T.P. Long-Term Change in Pearsonal Income Distribution: Theoretical Approaches, Evidence and Explanations. em Donald M. Levine e M.J. Bane (eds) The "Inequality" Controversy: Schooling and Distributive Justice. New York: Basic Book, 1975.

Senna, J.J. Escolaridade, Experiência no Trabalho e Salários no Brasil. Revista Brasileim de Economia, 30 (2): 163-193, 1976.

Shorrocks, A.F. Ranking Income Distributions. Economica, 50: 3-17, 1983.

Tilak, J.B.G. Education and its Relation to Economic Growth, Poverty and Income Distribution: Past Evidence and Further Analysis. World Bank Discussion Paper, 46: 1989.

Tinberger, J. The Impact of Education on Income Distribution. Review of Income and Wealth, 18:255-265, 1972.

Winegarden, C.R. Schooling and Income Distribution: Evidence from International Data. Economica, 46: 83-87, 1979. 


\section{APÊNDICE}

Tabela 3.

Distribuiçāo dos rendimentos para

grupos etários trianuais homens

com rendimentos positivos,

PNAD de 1976 e 1982

\begin{tabular}{ccccccccccc}
\hline & \multicolumn{4}{c}{ PNAD de 1976 } & \multicolumn{1}{c}{ PNAD de 1982 } \\
\cline { 2 - 11 } Idade & $N$ & $V(\ln Y)$ & $\dot{\beta}$ & $R^{2}$ & $V(u)$ & $N$ & $V(\ln Y)$ & $\dot{\beta}$ & $R^{2}$ & $V(u)$ \\
\hline$(1)$ & $(2)$ & $(3)$ & $(4)$ & $(5)$ & $(6)$ & $(7)$ & $(8)$ & $(9)$ & $(10)$ & $(11)$ \\
$22-24$ & 8740 & 0,631 & 0,117 & 0,304 & 0,439 & 11487 & 0,558 & 0,107 & 0,305 & 0,388 \\
$25-27$ & 8184 & 0,791 & 0,138 & 0,411 & 0,466 & 10862 & 0,721 & 0,127 & 0,408 & 0,427 \\
$28-30$ & 7829 & 0,931 & 0,156 & 0,467 & 0,496 & 10283 & 0,871 & 0,141 & 0,464 & 0,438 \\
$31-33$ & 6256 & 1,007 & 0,167 & 0,499 & 0,505 & 9386 & 0,936 & 0,153 & 0,508 & 0,460 \\
$34-36$ & 6356 & 0,953 & 0,167 & 0,425 & 0,548 & 8246 & 1,017 & 0,156 & 0,515 & 0,493 \\
$37-39$ & 5730 & 0,970 & 0,165 & 0,433 & 0,550 & 7262 & 1,014 & 0,160 & 0,504 & 0,503 \\
$40-42$ & 5563 & 1,007 & 0,170 & 0,434 & 0,570 & 7066 & 1,020 & 0,167 & 0,490 & 0,521 \\
$43-45$ & 4735 & 1,032 & 0,174 & 0,347 & 0,581 & 5991 & 1,023 & 0,171 & 0,467 & 0,545 \\
$46-48$ & 4410 & 1,052 & 0,176 & 0,419 & 0,611 & 5202 & 1,056 & 0,167 & 0,434 & 0,598 \\
$49-51$ & 3811 & 1,051 & 0,181 & 0,415 & 0,615 & 4556 & 1,066 & 0,172 & 0,437 & 0,600 \\
$52-54$ & 3223 & 1,095 & 0,181 & 0,406 & 0,651 & 4179 & 1,023 & 0,171 & 0,414 & 0,600 \\
$55-57$ & 2424 & 1,064 & 0,178 & 0,361 & 0,680 & 3367 & 1,016 & 0,163 & 0,348 & 0,662 \\
$58-60$ & 2075 & 1,130 & 0,187 & 0,397 & 0,681 & 2579 & 1,014 & 0,168 & 0,384 & 0,624 \\
$22-60$ & 69336 & 0,951 & 0,152 & 0,385 & 0,585 & 90466 & 0,921 & 0,142 & 0,408 & 0,545 \\
\hline
\end{tabular}

Ver Tabela 2 para notas 